Gerión. Revista de Historia Antigua

ISSN: 0213-0181

http://dx.doi.org/10.5209/GERI.59928

\title{
El "silencio" de Hidacio de Chaves. Las transformaciones religiosas en la Hispania del siglo V
}

\section{Rosa Sanz Serrano ${ }^{1}$}

Recibido: 21 de agosto de 2017 / Aceptado: 22 de diciembre de 2017

Resumen. El presente trabajo pretende demostrar que la "Crónica" de Hidacio, la fuente principal para el estudio de las Hispanias en el siglo V, es insuficiente para documentar las transformaciones religiosas que tuvieron lugar en su época. Especialmente la extensión del cristianismo y la desaparición de los cultos paganos en el norte peninsular, debido a su claro interés por dejar al paganismo fuera de su obra, principalmente con el silencio informativo sobre "los dominios de los dioses".

Palabras clave: transformaciones religiosas; paganismo; "dominios de los dioses"; cristianismo; Prisciliano.

\section{[en] The "Silence" of Hidacio of Chaves. The religious changes in Hispania during the Vth Century}

\begin{abstract}
The following essay proves that the "Chronic" by Hidacio, which is the main source for the study of the "Hispanic" in the Vth century, is insufficient for documenting the religious changes that took place in that era. Specially for the disappearance of the pagan cults and expansion of Christianity in the north of the peninsula, because of his clear interest in erasing the paganism out of his work, particularly the "dominance of the gods" through informative silence.
\end{abstract}

Keywords: Religious changes; Paganism; The possessions of Gods; Christianity; Priscillian.

Sumario: 1 . Hidacio y el paganismo peninsular. 2. Hidacio y los centros de culto cristiano. 3. Alternativas arqueológicas al "silencio" de Hidacio. 4. Referencias bibliográficas.

Cómo citar: Sanz Serrano, R. (2017): El "silencio" de Hidacio de Chaves. Las transformaciones religiosas en la Hispania del siglo V, en Gerión 35(2), 645-666.

\footnotetext{
$1 \quad$ Universidad Complutense de Madrid.

E-mail: rosasanz@ucm.es
} 


\section{Hidacio y el paganismo peninsular}

A comienzos del siglo V el obispo Sinesio de Cirene en su De regno ${ }^{2}$ defendía el necesario sometimiento de los ciudadanos al cambio moral, de costumbres y de educación que el monarca, con pleno derecho sobre sus almas, imponía en nombre de Dios. Con ello no hacía otra cosa que justificar la dura legislación de los emperadores de la dinastía Teodosiana contra los paganismos y cualquier desviación religiosa o ideológica dentro o fuera del cristianismo; legislación que había dado luz verde al cierre de los templos y de los lugares de culto y a la persecución violenta de quienes eran considerados paganos o heréticos. ${ }^{3}$ Las medidas tomadas supusieron el trasvase de una parte de los bienes de los paganos rebeldes a familias cristianas y a la Iglesia como institución y un importante aporte de riquezas a las arcas de un estado muy necesitado de ellas. Pero al mismo tiempo determinaron la pérdida de los privilegios de la ciudadanía romana, en especial para poderosos antagonistas como el sacerdocio de los grandes centros de culto y la nobleza pagana reacia a la conversión, con todo lo que ello implicaba respecto a sus derechos, bienes y vidas. ${ }^{4}$ De manera que el matrimonio entre Iglesia y Estado estuvo también destinado desde el primer momento a impedir el mantenimiento de un supuesto tercer poder constituido por los paganismos tardíos que, especialmente en las provincias, estuvieron dispuestos a promover y mantener los movimientos secesionistas. ${ }^{5} \mathrm{El}$ hecho de que una de esas leyes, emitida por los emperadores Honorio y Arcadio en el año 399 estuviera dirigida a "Macrobius vicario Hispaniarum et Procliano vicario quinque provinciarum" demuestra que las provincias hispanas no se quedaron al margen de la persecución. ${ }^{6}$

Sin embargo, el cambio religioso fue un proceso de largar duración presente en sus distintos aspectos en los más variados documentos de finales del siglo IV y del $\mathrm{V}$ en diversos lugares del Imperio, en especial en Oriente y África donde destacan los testimonios de Agustín de Hipona, Libanio de Antioquía y Sinesio de Cirene. ${ }^{7}$ En sus obras podemos apreciar situaciones de convivencia entre paganos y cristianos en todos los niveles sociales, al mismo tiempo que duros relatos de violencia institucional como testimonios de las transformaciones religiosas e ideológicas que se estaban operando en la sociedad romana, principalmente en los principales centros urbanos. Por el contrario, no contamos con tal bagaje de documentación para el Imperio de Occidente donde debemos sumar a la pobreza documental de la época el poco inte-

\footnotetext{
Synes. Regn. 25d-28c.

Aunque Constantino iniciara el proceso con la prohibición de la realización de sacrificios domésticos, fue la Dinastía Teodosiana la que desarrolló una legislación ordenada y sistemática (C.Th. 9.16.1-7; 16.9-12; 16.10.4). Ante el volumen historiográfico de la persecución del paganismo, remito principalmente a Joannou 1972 y Fowden 1993; sobre sus consecuencias en la Península Ibérica Sanz Serrano 2003.

$4 \quad$ Así lo defienden Lepelly 2001, 400, y North 2000.

5 Edward Gibbon no daba más de un 5\% de población cristiana a la llegada de Constantino al poder, sin embargo se ha defendido un aumento muy rápido de las conversiones, aunque lo cierto es que cualquier cálculo es meramente especulativo. Al respecto Cruz 2010, 235-272. En Hispania las luchas ideológicas de la aristocracia están presentes todavía en el reino visigodo de Toledo; al respecto Sanz Serrano 1986, 275-288.

C.Th. 16.10 .5 .

Agustín de Hipona en Conf. 1.9.14; 1.11.17-18; 2.3.5; 3.3.5; 6.10; 5.5.8; 8.14; 12.21. También señala la cristianización de las familias dominantes en Conf. 7.56.1-6; 9.13-14; 8.5.1-6; 9.3.5. Desde el punto de vista pagano destaca Libanio de Antioquía en Aut. 92-93; 106-129; 221-227 y 271; Orat. 2.22-48 y 45.4-17. De Sinesio destaca su epistolario y se puede consultar Cameron 1985, 218, y Cameron - Long 1993. Sobre la literatura de esta época el trabajo de Beard 1991, 35-58, y sobre la corte de Arcadio Hagl 1997. Un buen análisis general en Le Bohec 2005, 206, y Sanz Serrano 2011a, 56-76, y 2011b, 17-44.
} 
rés de las fuentes por informar sobre cuestiones religiosas y más preocupadas por la difícil situación política y militar de sus fronteras. Aunque podemos considerar una excepción la Galia donde los testimonios discrepantes de Martín de Tours -un claro ejemplo de intolerancia religiosa, destructor de templos y fundador de monasterios-, y Ausonio -defensor de las artes liberales y de la paideia vinculada a los templos paganos pero también de los nuevos valores cristianos- son un buen testimonio de los cambios estructurales y del proceso imparable de conversión al cristianismo, incluso entre la aristocracia más poderosa. ${ }^{8}$

En el conjunto de los testimonios sobre Occidente destaca la pobreza informativa sobre las Hispanias durante los siglos IV y V en claro contraste con la abundante documentación de época visigoda. Este desequilibrio cronológico responde primero a la inactividad conciliar del primer periodo, demostrativa de la precariedad territorial del cristianismo hispano. De hecho solo el temprano Concilio de Elvira contiene referencias a las prácticas paganas de los recientes conversos cristianos en la Bética que seguían manteniendo ídolos en sus casas y acudiendo a los templos. ${ }^{9}$ Pero principalmente al premeditado silencio del obispo Hidacio de Chaves, cuya Crónica es la única fuente de información histórica para el siglo $\mathrm{V}$ que nos ha llegado. Fuera de ella solo contamos con una declaración de principios y una serie de noticias sueltas e inconexas sobre acciones de los paganos en la provincia de la Tarraconense. La declaración de principios corresponde al prólogo de las Historiae adversus paganos del hispano Orosio quien, desde su autoexilio en el norte de África huyendo de los bárbaros, justificaba la redacción de su obra como mandato de Agustín de Hipona para que "escribiera contra la vana maldad de aquellos que, ajenos a la ciudad de Dios, son llamados paganos por los pueblos y villas del campo en que viven, o gentiles porque gustan de las cosas terrenas". ${ }^{10} \mathrm{El}$ autor pretendía denunciar a quienes permanecían ignorantes en el pasado, poco preocupados por el futuro y desconocedores de la cada vez mayor adoración a Dios y menor a los ídolos; a esos infieles, desobedientes e incrédulos que difícilmente podían nunca llegar a ser creyentes según su propio pensamiento. A pesar de ello y como paradoja su obra no contiene ningún tipo de datos sobre el paganismo peninsular o, si los hubo, la información ha desaparecido.

Con la misma indefinición y décadas después, tres manifestaciones literarias demuestran el mestizaje que se estaba produciendo en las ciudades entre paganos y cristianos: la carta del papa Siricio al obispo Himerio de Tarragona en que denunciaba al gran número de apóstatas, gentes sin bautizar y apegados al culto de los ídolos que existían en su sede; la recriminación del obispo Paciano de Barcelona a sus fieles por acudir a las fiestas paganas; y la queja del obispo Silvano de Calahorra sobre la extensión de vanissimam superstitionem en la provincia. ${ }^{11} \mathrm{~A}$ ellos podemos añadir una noticia externa procedente del obispo Salviano de Marsella quien en su De gubernatione Dei, tras referirse a la situación extrema de pobreza en Hispania, que el obispo atribuye a una política fiscal asfixiante y a los abusos de los jueces y

Sulp. Sev. VM. 12.30. Sanz Serrano 2003, 65, y sobre la corte de Honorio y Estilicón Sanz Serrano 2016, 213136.

9 Cs. 40, 41, 59 y 60 en Vives 1963, 12-15.

10 Oros. Hist., prólogo, 10 y 7.1.1-4.

11 PL. 13. 1132-1147, Paraenesis I. 2-3 y Grosse Fontes IX. 84, respectivamente. Al respecto Sanz Serrano 2013, 109. 
magistrados, dedica un comentario a los errores de quienes, viviendo bajo el nombre de cristianos, lo hacían en las impurezas del siglo, semejantes a los paganos o aun peores al ser conocedores de los mandatos de Dios. ${ }^{12}$ Lo interesante de los argumentos de este último autor es la desviación de la culpa hacia una nobleza territorial a quien las poblaciones habían entregado sus vidas, y se supone sus almas, y al hecho de que los hispanos no querían seguir siendo romanos, lo que implicaba, aunque él no lo dice, el rechazo de la religión del Imperio, el cristianismo. ${ }^{13}$

Como se evidencia la información presentada es insuficiente para un estudio mínimo de las transformaciones religiosas en los territorios hispanos en el siglo V. Sin embargo, y aunque resulte contradictorio, podemos obtener mejores resultados de la fuente supuestamente más estéril respecto al paganismo, la Crónica de Hidacio de Chaves. Se trata de la obra más extensa de este siglo sobre las provincias hispanas destinada a informar a los cristianos sobre un mundo exclusivamente cristiano en el que los paganos no tenían ya cabida a pesar de su todavía existencia. Pues el autor escribió para los ciudadanos de las Hispanias con la convicción de que los paganos no podían ser considerados como tales (como también vimos reflejaba Salviano de Marsella) si actuaban en contra de los deseos y las leyes de sus emperadores, aunque su peso político y económico fuese todavía significativo. Como reciente converso, según él mismo acepta, "Hydatii ad Deum conversio peccatoris", ${ }^{14}$ su obra es prefigurativa, un exemplum, que le obligó a centrar su atención en los hechos eclesiásticos, en las figuras de los emperadores cristianos, sus enemigos internos y externos, su lucha contra las herejías y a dejar de lado los aspectos sociales y económicos y el evidente declive de las instituciones romanas y de la organización militar que dañaban a todos los estratos de la ciudadanía. ${ }^{15}$ Pero sobre todo en ella no hay lugar para las creencias de los hispanos fuera de las impuestas por el Estado, aunque sí para el paganismo del enemigo, del bárbaro causante de dolor como el vándalo Gunderico, ${ }^{16}$ el suevo Heremigario, ${ }^{17}$ los visigodos de reciente conversión al arrianismo pero todavía con creencias paganas arraigadas, ${ }^{18} \mathrm{o}$ el proveniente de la barbarie interna, la bagauda. ${ }^{19}$ Pues su obra en esencia estuvo principalmente dirigida a exponer los episodios de violencia desencadenados por los bárbaros paganos o herejes -después de su entrada en las provincias hispanas en el año 409- sobre poblaciones supuestamente cristianas puestas a prueba por la providencia divina: "Barbari, qui in Hispanias ingressi fuerant, caede depraedatur hostili" ${ }^{20}$ Este interés obligó al autor a presentar en su narración a los hispanos como un bloque social e ideológico homogéneo muy a pesar de las existentes diferencias culturales, socioeconómicas, políticas e ideológicas de los distintos territorios provinciales. ${ }^{21}$

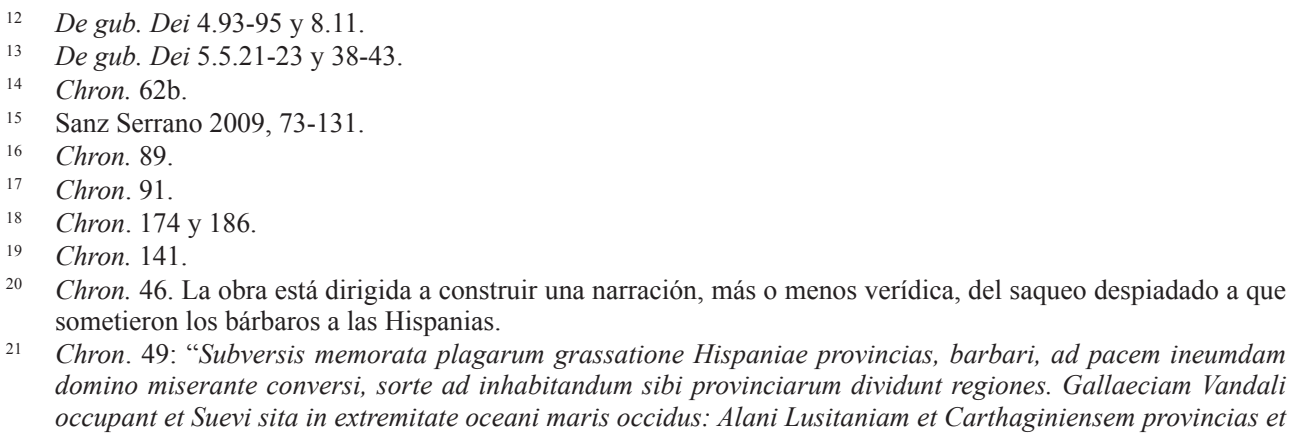

21 Chron. 49: "Subversis memorata plagarum grassatione Hispaniae provincias, barbari, ad pacem ineumdam domino miserante conversi, sorte ad inhabitandum sibi provinciarum dividunt regiones. Gallaeciam Vandali occupant et Suevi sita in extremitate oceani maris occidus: Alani Lusitaniam et Carthaginiensem provincias et 
El fin perseguido por Hidacio supone una construcción histórica forzada donde resaltan varios elementos: la clara disparidad entre el número elevado de correrías y depredaciones de los bárbaros en el campo y en los centros urbanos, civitates et castella, y la total ausencia de datos sobre las destrucciones de templos paganos; los reducidos casos explícitos de la presencia de cristianos y edificios de culto, localizados todos en unos pocos centros urbanos; y la coincidencia del mapa del cristianismo que dibuja con los principales focos del movimiento priscilianista. Si seguimos este orden, es especialmente significativo el silencio de Hidacio sobre las más que probables destrucciones y saqueos de lugares de culto en los espacios rurales, todavía más cuando el autor testimonia un buen número de situaciones de depredación y expolio entre los años 429 y 460. Primero los saqueos de los suevos en el norte peninsular dirigidos por Hermerico en 429 con muchas muertes y prisioneros procedentes de las poblaciones rurales, ya que la plebe se había refugiado en los centros amurallados: ${ }^{22}$

Suevi, sub Hermerico rege, medias partes Gallaeciae depraedantes, per plebem, quae castella tutiora retinebat, acta suorum partim caede, partim captivitate, pacem quam ruperant familiarum quae tenebantur redhibitione restaurant.

Después la expedición de saqueo de Requila en 438 por territorios de la Bética y la Cartaginense, en el transcurso de la cual se produjo uno de los enfrentamientos con los hispanos mejor documentado por Hidacio, el que tuvo lugar contra un tal Andevoto en el Genil, que reportó a los suevos grandes riquezas en oro y plata: ${ }^{23}$

Hermericus rex, morbo oppressus, Rechilam filium suum sustituit in regnum: qui Andevotum cum sua, Quam habebat, manu ad Singillionem Baeticae fluvium aperto marte prostravit magnis Rius auri et argenti opibus occupatis.

En este caso es más que probable que el botín proviniese de las ricas villas enclavadas en las riberas del río y de los antiguos templos paganos que podrían estar todavía en funcionamiento, pues el silencio sobre el origen impide pensar en iglesias cristianas cuyo expolio siempre está resaltado en la Crónica como veremos más adelante. Tras estas noticias, Hidacio da un salto cronológico para denunciar desde el año 447 los saqueos de los suevos al mando del nuevo jefe Requiario por amplios espacios de la Lusitania, la Bética y la Cartaginense: "obtento tamen regno sine mora ulteriores regiones invadit ad praedam", ${ }^{24}$ las depredaciones por la Vasconia cuando el jefe suevo volvía de la Galia de desposar a la hija del godo Teodorico:25 "Vasconia depraedatur", y en el año 456 por la Tarraconense de donde obtuvo un buen número

Vandali, cognomine Silingi, Baeticam sortiuntur. Hispani per civitates et castella residui a plagis barbarorum per provincias dominantium se subiciunt servituti". El pacto de Honorio con los godos para expulsarlos de las provincias determinó nuevos enfrentamientos entre los distintos grupos como se comprueba en Chron. 60-70.

22 Hacia 429, en Chron. 91.

23 Chron. 114. También Chron. 123: "Rex Rechila, Hispali obtenta, Baeticam et Carthaginiensem Provincias in suam redigit potestatem".

24 Año 449, en Chron. 137 y también 134: "Vitu, magister utriusque militiae factus, ad Hispanias missus non exiguae manus flutus auxilio, cum Carthaginienses vexaret et Baeticos, succedentibus cum rege suo illic Suevis, superatis etiam in congressione, qui ei ad depraedandum in adiutorium venerant, Suevi exim illas provincias magna depraedatione subvertunt Gothis, territus miserabili timore dinunit".

25 Año 449, Chron. 140: "Rechiarius, acdepta in coniugium Theodorici regis filia auspicatus initium regni Vasconias depraedatur, mense Februario". 
de cautivos: ${ }^{26}$ "provinciae Terraconensis invadit acta illic depraedatione et grandi ad Gallaeciam captivitate deducta". Al mismo tiempo documenta las campañas de castigo de las tropas imperiales y sus federados godos indistintamente contra bárbaros e hispanos por estas provincias, sin que haya una sola alusión a la situación de los edificios paganos enclavados en ellas. Como sería el caso de los situados en la rica zona minera de la región de Astorga, importante enclave militar, cuando Requiario se enfrentó a los godos federados del emperador Avito dirigidos por Teodorico en la conocida batalla del río Órbigo, a doce millas de la ciudad, donde consiguió muchos prisioneros. ${ }^{27}$ Predomina también su silencio respecto a los centros de culto cuando pocos años después presenta a los suevos, divididos en bandas dirigidas por distintos jefes como Maldrás y Requismundo, asolando durante quince años los campos de Lusitania, la ribera del Duero, las regiones del Miño habitadas por los Auregenses y Aunonenses y los conventos lucense y asturicense. ${ }^{28}$ Incluso cuando los godos federados causaron desolación en en el intento de recuperar las provincias para el Imperio, principalmente en la Lusitania y "Caesaraugustam regionem", sin que sepamos nada sobre el peligro que corrieron los lugares sagrados situados en el campo. ${ }^{29}$ No es menor el silencio del cronista respecto a las consecuencias para los edificios públicos de la violencia de los saqueos provocados por los actos piráticos de los vándalos en el año 445 en la desembocadura del Miño, en Turonio donde fueron capturadas muchas familias, ${ }^{30}$ ni de los érulos en las costas de Lugo, de Cantabria y de la Vardulia entre los años $455-457 .{ }^{31}$

Ante la evidente falta de información sobre los daños que sufrieron los centros de culto conocidos y atestiguados por otras disciplinas, algunos de fundación muy antigua, es inmediato suponer que podría deberse a que en esta época estuviesen ya abandonados y reemplazados por edificios cristianos. Pero esta lógica contrasta con la también total ausencia de referencias concretas a iglesias rurales a pesar de su interés por testimoniar la cristianización del norte peninsular. Por el contrario, cuando nos llegan en su obra los datos sobre saqueos y destrucciones de iglesias están relacionados siempre con centros urbanos y no son numerosos, mientras que sigue manteniendo el silencio sobre los edificios de culto pagano en ellos. La escasez de casos sobre centros cristianos puede deberse a varias razones: su inexistencia en unos momentos todavía muy tempranos en la expansión del cristianismo hacia el

26 Año 456, Chron. 168-170 y 172.

27 Chron. 173.

28 Chron. 188: "Suevi in partes divisi pacem ambiunt Gallaecorum: e quibus pars Framtano, pars Maldras regem appellant. Solito more perfidiae Lusitaniam depraedatur pars Suevorum Maldarem sequens". También Chron. 202: "Rechimiumdus vicina sibi pariter Auregemsium loca et Lucensis conventus maritima populatur". Acciones repetidas hasta el año 462 sobre los aunonenses del Miño y el Tuy, en Chron. 233: "Suevi adversus Aunonensem saeviunt plebem. Qua de causa legati a Theodorico ad Remismundum mittuntur in cassum spretique ab eo mox redeunt". De nuevo en Chron. 249: "Aunonenses pacem cum rege taciunt Suevonim, qui et Lusitaniae et conventus Asturicensis quaedam loca praedantes invadunt".

29 Chron. 250: "Gothi circa eundem conventum pari hostilitate desaeviunt; partes etiam Lusitaniae depraedantur", o juntos godos y bagaudas en el convento caesaraugustano hacia el 449 en Chron. 142: "Rechiarius, mense Iulio ad Theodoricum socerum profectus, Caesaraugustam regionem cum Basilio in reditu depraedatur. Inrupta per dolum Ilerdensi urbe acta est non parva cautivitas".

30 Chron. 131.

31 Chron. 171 y, sobre todo, en Chron. 194: "De Erulorum gente Septem navibus in Lucensi litore aliquanti aduecti, viri ferme CCCC expediti, superventu multitudinis congregatae duobus tantum ex suo numero effugantur occisis: qui ad sedes proprias redeuntes Cantabriarum et Vardulliarum loca maritima crudelissime depraedati sunt". 
norte $\mathrm{o}$, lo menos probable, que las iglesias fueran respetadas en algunos centros por los mismos bárbaros que no tuvieron ningún inconveniente en saquear y destruirlas en otros lugares. $\mathrm{O}$, por el contrario, al hecho de que los templos paganos estuviesen todavía en funcionamiento e Hidacio no quiso dejar constancia de su saqueo y prefirió llevar a cabo la damnatio memoriae de los mismos en su obra.

Si nos centramos en los centros urbanos y si descartamos los asedios de Braga y Tarragona por los vándalos en los años 419 y 422 respectivamente, ${ }^{32}$ las primeras ciudades que sufrieron un asalto fueron Cartagena y Sevilla por parte de los vándalos antes de pasar al norte de África: ${ }^{33}$ "Quique Carthagine Spartaria et Hispali eversa et Hispaniis depraedatis Mauretaniam invadunt", sin que haya información sobre las consecuencias para sus lugares de culto paganos o supuestamente ya existentes cristianos. Tampoco cuando pocos años después el suevo Requila entró en Mérida sin causar daños y allí vivió y murió ${ }^{34}$ ni cuando su hijo Requiario entró violentamente en Sevilla hacia el año 438:" "Rex Rechila, Hispali obtenta, Baeticam et Carthaginiensem Provincias in suam redigit potestatem". El silencio predomina respecto a saqueos posteriores como los sucedidos por parte de los suevos en el norte peninsular, en la ciudad de Ulixippo (Lisboa), ${ }^{36}$ el asentamiento militar de Lucus, donde incluso murieron algunos de sus principales habitantes, ${ }^{37} \mathrm{o}$ en el castro de Portumcale ${ }^{38}$ El tipo de información no varía cuando en el año 459 los comites Sunerico y Nepociano, con ejércitos imperiales, depredaron de nuevo Lugo y un lugar próximo denominado Dictinio, aunque por primera vez Hidacio deja constancia de la existencia de una iglesia en su obispado de Aquae Flaviae (Chaves) en el que él mismo fue hecho prisionero por los suevos: ${ }^{39}$

Ac mox, isdem delatoribus quibus supra, Frumarius, cum manu Suevorum Quam habebat, impulsus, capto Hydatio episcopo VII kal. Aug. In Aquaeflaviensi ecclesia, eundem conventum grandi evertit excidio.

La obra hidaciana continúa relatando la entrada por la fuerza del suevo Sunierico en el año 460 en Scalabis (Santárem):40 "Sunericus Scallabim, cui adversabatur, optinet civitatem" y en el año 462 en Conimbriga (Condeixa-a-Nova) donde se produjo un violento expolio y de donde se llevó cautiva a la familia del noble cántabro: ${ }^{41}$ "Suevi, Conimbricam dolose ingressi, familiam nobilem Cantabri spoliant et captivam abducunt matrem cum filiis" y un nuevo saqueo poco tiempo después al que se

32 Primero en Braga los vándalos asediaban a los suevos que fueron ayudados por las tropas del comes de las Hispanias Asterius en Chron. 74. Tarraco como lugar de refugio de Castino cuando luchaba contra los vándalos en la Bética en Chron. 77.

33 Año 425, en Chron. 86: "Vandali Baliaricas insulas depraedantur. Quique Carthagine Spartaria et Hispali eversa et Hispaniis depraedatis Mauretaniam invadunt".

34 Chron. 119: "Rechila, rex Suevorum, Emeritam ingreditur".

35 Año 440, en Chron. 123.

36 Año 457, en Chron. 188: "Suevi in partes divisi pacem ambiunt Gallaecorum: e quibus pars Framtano, pars Maldras regem appellant. Solito more perfidiae Lusitaniam depraedatur pars Suevorum Maldarem sequens. Acta illic Romanorum caede praedisque contractis "civitas" Ulixippona sub specie pacis intratar".

37 Año 457, en Chron. 199: "Per Suevos, Luco habitantes, in diebus Paschae, Romani aliquanti cum rectore suo honesto natu, repentino, securi de reverentia dierum, occiduntur incursu".

38 Chron. 175: "Maldras germanum suum fratrem interficit et Portumcale castrum idem hostis invadit".

39 Año 460, en Chron. 201.

40 Chron. 206.

41 Chron. 229. Sobre los niveles de incendio del centro urbano véase Bairrão - Étienne 1965, 422-451. 
sumó la destrucción de sus casas y la dispersión de sus habitantes sin que sepamos de posibles daños a edificios religiosos de culto pagano o cristiano: 42 "Conimbriga, in pace recepta, diripitur domus destruuntur cum aliqua parte murorum habitatoribusque captis atque dispersis et regio desolatur et civitas". Mantiene igualmente el silencio en la definitiva ocupación de Ulixippo por los suevos gracias a la traición de uno de sus habitantes:43 "Ulixippona a Suevis occupatur, cive suo, qui illic praeerat, tridente Lusidio" y en el asalto de los bagaudas a la ciudad de Ilerda cuando llevaban a cabo una campaña de saqueo por la región de Caesaraugusta hacia el año $449 .{ }^{44}$

\section{Hidacio y los centros de culto cristianos}

Por lo tanto, en la desolación que presenta su obra se explica la ausencia de los edificios de los antiguos cultos en las civitates et castella por cuestiones ideológicas, pero no sucede lo mismo con su silencio respecto a los edificios cristianos, también en los centros urbanos. De hecho son minoritarias las descripciones de su existencia y destrucción a pesar de que están localizados en cuatro provincias diferentes. El primero hacia el 425 como consecuencia del saqueo de Sevilla por las tropas del vándalo Gunderico quien con su impiedad y soberbia puso sus manos sacrílegamente sobre su iglesia, lo que le costó la vida como castigo divino y permitió el reinado de su hermano Gaiserico que se hizo arriano: ${ }^{45}$

Gundericus, rex Vandalorum, capta Hispali, cum impie elatus manus in ecclesiam civitatis ispsius extendiste, mox dei indicio daemone correptus interiit: cui Gaisericus frater succedit in regno qui, ut aliquorum relatio habuit, effectus apostata de fide católica in Arrianam dictus est transisse perfidiam.

Mientras el segundo se refiere a la muerte no lejos de Mérida del jefe suevo Heremigario precipitado por el brazo de Dios al río Anas por haber injuriado a la santa mártir Eulalia, es decir, a su santuario: ${ }^{46}$

Qui haud procul de Emerita, Quam cum sanctae martyris Eulaliae iniuria spreverat, maledictis per Gaisericum caesis ex his quos secum habebat, arrepto, ut putavit, euro velocius fugae subsidio, in fluminis Ana divino brachio praecipitatus interiit.

42 Chron. 241.

43 Chron. 246.

44 Chron. 142: "Rechiarius, mense Iulio ad Theodoricum socerum profectus, Caesaraugustam regionem cum Basilio in reditu depraedatur. Inrupta per dolum Ilerdensi urbe acta est non parva cautivitas".

45 Año 425, en Chron. 89.

46 Año 429, en Chron. 90: "Gaisericus rex, de Baeticae provinciae litore, cum Vandalis omnibus eorumque familias, mense Maio ad Mauretaniam et Africam relictis transit Hispaniis. Qui, priusqueam pertransiret admonitus Heremigarium Suevum vicinas in transitu suo provincias depraedari, recursu cum aliquantis suis facto praedantem in Lusitania consequitur. Qui haud procul de Emerita, Quam cum sanctae martyris Eulaliae iniuria spreverat, maledictis per Gaisericum caesis ex his quos secum habebat, arrepto, ut putavit, euro velocius fugae subsidio, in fluminis Ana divino brachio praecipitatus interiit. Quo ita extincto mox quo coeperat Gaisericus enavigavit". Los godos intentaron de nuevo el expolio del santuario de Eulalia en el año 456 como se comprueba en Chron. 182, pero fueron aterrorizados por una serie de prodigios que lo evitaron "Theodoricus, Emeritam depraedari moliens, beatae Eulaliae martyris terretur ostentis". 
En la primera referencia surge la duda sobre la situación de la iglesia hispalense dentro o fuera de los muros de la ciudad, pero en el caso del santuario de Eulalia de Mérida sabemos que estaba fuera de su recinto, en una domus privada y, en consecuencia, con fácil acceso y con pocas posibilidades de defensa. Por lo tanto ninguno de los dos casos demuestra la existencia de iglesias en los recintos urbanos ni la ausencia de templos paganos en ellos. Pero con ambos testimonios Hidacio presenta como cristianas dos de las ciudades más importantes de las provincias lusitana y bética. Por la misma razón el tercer episodio de su relato se desplaza hacia una tercera provincia, la Tarraconense, donde tuvieron lugar las correrías de los bagaudas de Basilio que en el año 449 mataron a los soldados federados del imperio y al obispo León en la iglesia de Tyriasso (Tarazona), cuya localización tampoco se señala y no parece probable que estuviera dentro de las murallas porque en ningún momento se habla de la toma de la ciudad:47

Basilius, ob testimonium egregii ausus sui, congregatis Bacaudis in ecclesia Tyriassone foederatos occidit. Ubi et Leo eiusdem ecclesiae episcopus ab isdem, qui cum Basilio aderant, in eo loco obiit vulneratus.

Una vez cubiertas las tres provincias más relevantes, Hidacio ignora la provincia Cartaginense y se concentra en la Gallaecia, donde vivía y donde su relato alcanza los niveles más altos de dramatismo nada menos que en cuatro casos. De ellos, el escenario más cruel se dibuja hacia el 457 , con los asaltos de los godos federados del Imperio al mando de su caudillo Teodorico a la ciudad de Braga, la última de la provincia según el cronista, un 30 de octubre. En él Hidacio niega el derramamiento de sangre al ser tropas enviadas por el emperador, pero admite que se llevaron gran cantidad de cautivos, derribaron las basílicas de los santos, destruyeron los altares, raptaron a las vírgenes de Dios aunque con su integridad salvada, despojaron al clero de sus vestidos y sacaron a toda la gente de ambos sexos con los niños de los lugares santos de refugio que sin lugar a dudas, aunque Hidacio no lo diga, saquearon. ${ }^{48}$ Poco después, y en su regreso a la Galia, una parte del ejército godo, mediante el engaño y la perfidia, entró en Astorga con la excusa de aliarse contra los suevos y atacó a sus habitantes sin distinción de raza; es decir, a suevos y a hispanos, al tiempo que saqueó los campos y quemó los edificios, derribó las santas iglesias y los altares y se llevó los ornatos y los utensilios de uso sagrado, además de al clero y al obispo en cautividad; acciones que repitieron los godos en la "Palentina civitas", donde por otra parte no se citan ni edificios ni clero cristiano, pero que no pudieron repetir en el "Coviacense castrum" cercano a Astorga, donde muy probablemente habría algún destacamento militar que evitó el saqueo. ${ }^{49}$

47 Año 449, en Chron. 141.

48 Año 455, en Chron. 174: "Theodorico rege cum excercitu ad Bracaram extremam civitatem Gallaeciae pertendente III kal. Novembris, die dominico, etxi incruenta, fit tamen Satis maesta et lacrimabilis eiusdem direptio civitatis, Romanorum magna agitar captivitas captivorum; sactorum basilicae effractae, altaria sublata atque confractan, virgines dei exim quidem abductae, sed integritatem servatam, cleros usque ad nuditatem pudores exutus, promiscui sexus cum parvulis de locis refugii sanctis populus omnis abstractus iumentorum pecorum camelorumque horrore locus sacer impletus, scripta super Hierusalem ex parte caelestis irae renonavit exempla".

49 Chron. 186: "Theodoricus, adversis sibi nuntiis territus, mox post dies paschae, quod fui II kal. Aprilis, de Emerita egreditur et, Gallias repetens, partem, ex ea Quam habebat multitudine variae nationis, cum ducibus suis ad campos Gallaeciae dirigit: qui dolis et periuriis instructi, Sicut eis fuerat imperatum, Asturicam, Quam 
Si pasamos a recopilar, Hidacio señala acciones contra cristianos en cuatro provincias; la cartaginense está ausente pues solo una vez se nombra a Cartagena y sin aludir a que sufriera daños. De las cuatro provincias solo presenta en cinco ciudades edificios y sacerdocio cristiano: Hispalis en la Bética, Emerita en la Lusitania, Tyriasso en la Tarraconense, Bracara Augusta y Asturica Augusta en la Gallaecia, pues el dato sobre Palencia es dudoso. A ellas tendremos que añadir la sede episcopal de Hidacio, Aquae Flaviae. De estos centros, Hispalis tiene un gran protagonismo en la Bética en la Antigüedad Tardía y el resto fueron capitales de provincia o de convento y posibles centros militares desde donde se controlaba la zona minera del noroeste. Todas ellas, a excepción evidente de Tyriasso, están situadas en las vías que comunican el noroeste peninsular con la Bética y que unen los centros de Olissipo y Bracara con Hispalis pasando por Mérida. El resto de los centros citados por Hidacio en su obra sin aludir a destrucción de iglesias como Lucus, Turonio, Dictinum, Portumcale, Scalabis, Conimbriga, Ulixippo y Myrtilis están también en relación con las principales arterias de comunicación del noroeste peninsular por donde los bárbaros llevaron a cabo sus expediciones y en ellos estuvieron enclavados importantes santuarios paganos en época prerromana y romana.

A la geografía religiosa cristiana de los saqueos debemos añadir los casos en que Hidacio testimonia la existencia de obispos. El principal Agrestio obispo en Lugo (donde no se habían producido destrucciones de edificios cristianos) en el año 435 y en conflicto con otros dos obispos recién nombrados, Pastor y Siagrio que habían escrito tratados contra los herejes. ${ }^{50}$ A su lado, los de sedes donde sí hubo ataques a iglesias: Sabino en Sevilla, el obispo Toribio de Astorga y Antonio de Mérida en $445^{51}$ y por supuesto León, el obispo muerto en Tarazona. A ellos se añaden un obispo en Celenis -donde se obligó a retractarse de sus creencias a los obispos priscilianistas Sinfosio y Dictinio ${ }^{52}$-, la sede hidaciana de Aquae Flaviae. Por lo tanto tampoco a través de los obispados se presenta una estructura demasiado consolidada. Aunque por otro lado las sedes obispales eran más numerosas como se comprueba en las actas de los concilios de Elvira, de Zaragoza del año 380 y I de Toledo del año 400. La razón de este desequilibrio informativo es que se interesa poco por las sedes que están enclavadas fuera de su provincia de la Gallaecia, salvo que existan en ellas polémicas religiosas muy probablemente relacionadas con el movimiento priscilianista que considero el iniciador e impulsor de la expansión del cristianismo en el norte. Este hecho nos lleva al análisis de uno de los aspectos más importantes de su Crónica que es la relación de las ciudades supuestamente cristianizadas del norte peninsular con el priscilianismo y la oposición al mismo en la que el propio Hidacio tuvo un papel relevante y fue un claro beneficiario.

iam paredones ipsius sub specie Romanae ordinationis intraverant, mentientes ad Suevos qui remanserant iussam sibi expeditionem, ingrediuntur pace fucata solita arte perfidiae. Nec mora, promiscui generis reperta illic caeditur multitudo, sanctae effringuntur ecclesiae, altaribus direptis et demolitis sacer omnis ornatus et usus aufertur. Duo illic episcopi inuenti cum omni clero abducuntur in captivitatem: invalidior promiscui sexus agitar miseranda cautivitas; resuduis et vacuis civitatis Dominus datis incendio, camporum loca vastantur. Palentina civitas simili quo Asturica per Gothos perit exitio. Unum Coviacense castrum tricesimo de Asturica miliario a Gothis diutino certamine fatigatum auxilio dei hostibus et obsistit et praevalet; Quam plurimus ex forum manu interfectis, reliquia revertuntur ad Gallias".

50 Chron. 102.

51 Chron. 130.

52 Chron. 23. 
No es el momento de analizar los entresijos del fenómeno priscilianista y de la persecución que sufrieron sus componentes. Pero sí de aclarar la relación de las ciudades que aparecen como cristianas en la Crónica de Hidacio con los principales centros donde se desarrolló el movimiento antes de que sus cabecillas fuesen perseguidos como herejes, ejecutados en Tréveris en el año 385 y sus bienes requisados por orden del emperador Máximo. ${ }^{53}$ Sulpicio Severo, el cronista de los hechos, señala que la represión vino por las denuncias de los obispos Higinio de Córdoba, Itacio de Ossonoba (Faro) e Hidacio, el metropolitano de Mérida, quienes veían peligrar su control del desarrollo del cristianismo en el norte peninsular por la influencia de los nobles Prisciliano, Instancio y Salviano a los que consideraban heréticos. En los primeros momentos del enfrentamiento ideológico y probablemente político los priscilianistas intentaron controlar la sede de Mérida, fundamental para el dominio de los territorios del norte, donde colocaron panfletos en contra de Hidacio y, ante el fracaso de su acción, decidieron nombrarse obispos de tres nuevas sedes más alejadas. Sulpicio Severo solo deja constancia de una de ellas, Abula, donde fue ordenado Prisciliano por obispos partidarios: ${ }^{54}$ "Priscillianus declinans in haeresem gnosticorum, per episcopos, quos sibi in eadem pravitate collegerat, Abulae episcopus ordinatur" y deja en suspenso el nombre de las otras dos. La identificación de esta civitas es polémica como también del resto, pero lo que es cierto es que la primera no aparece años después en la Crónica de Hidacio de Chaves como lugar con edificios de culto cristiano u obispados, lo que podría suponer que tras la ejecución de Prisciliano unas décadas antes, la sede episcopal no se hubiera mantenido. En cuanto a las otras dos, las de Instancio y Salviano, no me parece plausible que se trate ninguna de ellas de Hispalis, donde sí hubo posteriormente obispo, por quedar demasiado alejada del territorio en polémica, ${ }^{55}$ por lo que debemos buscar sus enclaves en el noroeste donde se perfilan como candidatas Lugo y Astorga. La primera porque en el año 457, según la Crónica hidaciana, en el conventus lucensis se consagró como obispos a Pastor y Siagrio contra la voluntad del obispo de Lugo, Agresto, lo que parece situarnos en una lucha entre partidarios de distintas corrientes de pensamiento cristiano aunque desconocemos exactamente las sedes que se crearon para ellos. ${ }^{56} \mathrm{La}$ segunda porque en su tiempo se descubrieron ciertos maniqueos que estaban ocultos (los priscilianistas fueron relacionados con los maniqueos) gracias a las actas episcopales que los obispos Hidacio de Chaves y Toribio de Astorga, que los habían escuchado, enviaron a Antonio, obispo de Mérida hacia el año 445;57 lo que demuestra una vez más que después de la muerte de Prisciliano y sus allegados, Mérida seguía teniendo jurisdicción sobre las sedes del norte donde se seguía persiguiendo cualquier tipo de heterodoxia. Hidacio recuerda un poco después que un maniqueo de Roma, un tal Pascencio, había huído de Astorga y fue arrestado en Mérida por el obispo que lo

\footnotetext{
En C.Th. 16.2.35; Prisc. Tract. 1.28 y 2 y Sulp. Sev. Chron. 2.46.6; 2.50 y 3.47.4 en la ed. Halm 1866, I, 99-105.

54 Chron. 2.48: "Priscillianus declinans in haeresem gnosticorum, per episcopos, quos sibi in eadem pravitate collegerat, Abulae episcopus ordinatur: qui aliquot episcoporum conciliis auditus Italiam petit et Romam, ubi ne ad conspectum quidem episcoporum Damasi et Ambrosii receptus cum his, cum quipus fuerat, redit ad Gallias. Inibi similiter a sancto Martino episcopo et ab aliis episcopis haereticus iudicatus appellat ad Caesarem".

55 Chron. 124.

56 Chron. 102. Sabemos por Genadio de Marsella (De Script. Eccles. 76; Migne PL 58, 1103) que Pastor y Siagrio habían compuesto tratados contra los herejes en los que no estaba incluido Prisciliano.

57 Chron. 130.
} 
expulsó de la provincia de Lusitania:58 "Pascentium quendam urbis Romae, qui de Asturica diffugerat, Manichaeum Antoninus epixcopus Emerita comprehendit auditumque etiam de provincia Lusitania facit expellit". Sin embargo, la presencia en los concilios de Zaragoza del año 380 y de Toledo del 400 del obispo Simposio y el hecho de que éste nombrara como sucesor en Astorga a un tal Dictinio, de marcado corte priscilianista, evita adjudicar la sede a Instancio o a Salviano. Piay Augusto ${ }^{59}$ mantiene además la hipótesis de que Simposio y Dictinio se hicieran cargo del traslado del cuerpo de Prisciliano a través de la Galia y de su enterramiento en un lugar donde después sabemos se le rindió culto, que él propone en Astorga.

Con lo que podemos acogernos a una tercera opción, la de un obispado en Braga donde hemos visto que la Crónica de Hidacio señala sacerdocio e iglesias, aunque no obispo en el episodio de su destrucción, años después de la desaparición de Prisciliano, de Instancio y de Salviano. De hecho, en el I Concilio de Toledo abjuraron del priscilianismo junto con Dictinio de Astorga, otros personajes como Anterio, Isonio, Vegetino y Paterno de los cuales solo se sabe la sede del último que era Braga y que pudo ser el sucesor de Instancio o Salviano, perseguidos junto con Prisciliano en el $385 .{ }^{60}$ También fueron juzgados Herenas, Donato, Acurio y Emilio de quienes desconocemos también las sedes, con lo que se frenó en parte la estructura eclesiástica priscilianista, en el norte y, con ello, el control del paganismo en esta zona. Por último, otras opciones son la sede de Aquae Flaviae, donde cincuenta años después estaba Hidacio como obispo -y de este modo se entiende también su interés extremo en la denuncia del movimiento cuya sede había heredado-, y Tyriasso, que aparece en la Crónica con iglesia pero que considero más alejada del núcleo central del priscilianismo. A pesar de ello no puede ser descartada, pues la conocida epístola 11 de Consensio a Agustín de Hipona ${ }^{61}$ destaca la lucha que éste llevó a cabo junto con Frontón, presbítero de Huesca que se había hecho pasar por priscilianista, por desenmascarar a los herejes y cómo supieron a través de la noble Severa, simpatizante priscilianista y pariente del comes Asterius, de la implicación en el movimiento de obispos de la provincia y de importantes aristócratas. Al parecer uno de los nobles, Severo, fue asaltado por los bárbaros que le robaron unos códices que entregaron al obispo Sagitio de Ilerda, defensor de los priscilianistas, quien a su vez los envió al metropolitano Titianus de Tarraco y éste, a su vez, a Siagrio de Osca que podría ser priscilianista o no. Por lo tanto, en la epístola se comprueba que el priscilianismo se había extendido también al noreste peninsular a comienzos del siglo V.

Las ciudades citadas (Bracara, Asturica, Abula, Lucus, Aquae Flaviae y Tyriasso) y su territorio eran espacios bien controlados por Roma y en manos de importantes aristocracias locales no solo por el desarrollo de la explotación de sus minas, sino también por la existencia de grandes latifundios agrícolas donde sabemos estuvieron enclavadas importantes villas. La importancia de los priscilianistas como parte de esta poderosa nobleza local se comprueba en la apelación primero ante el emperador Graciano y ante el papa Dámaso y Ambrosio de Milán donde tenían apoyos aunque fracasaron. ${ }^{62} \mathrm{Y}$ su influencia entre las poblaciones que dependían de

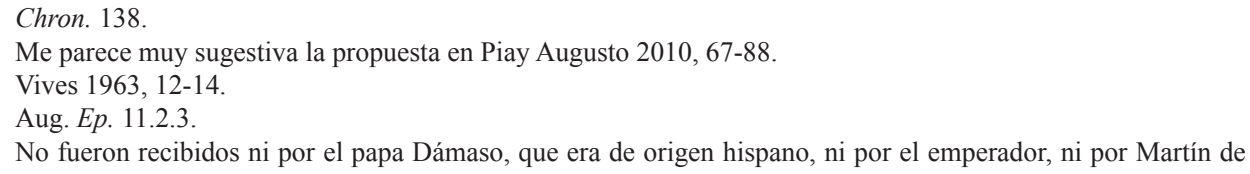


ellos justifica igualmente el traslado del cuerpo de Prisciliano, su aceptación como hombre santo, y la "invasión" de la herejía en Gallaecia a la que se refiere Hidacio: ${ }^{63}$ "Exim, in Gallaeciam Priscilianistarum haeresis invasit". También es demostrativa de su poder la preocupación que se refleja en la obra hidaciana por la pervivencia de elementos aferrados a sus doctrinas, del estigma que sufrieron, y por las reyertas entre priscilianistas y antipriscilianistas durante los siglos V y VI que tenían como finalidad el control ideológico de las poblaciones del norte peninsular. Aunque el silencio de Hidacio de nuevo oculta las causas sociales y económicas que hay tras el conflicto y el hecho de que los principales beneficiarios de los bienes de los priscilianistas tras la represión de la secta fueron la Iglesia y los sacerdotes ortodoxos entre los que se encontraba el obispo cronista.

Al mismo tiempo se da la paradoja de que el paganismo peninsular que Hidacio pretendía silenciar se esconde en el fenómeno priscilianista. No voy a analizar aquí la heterodoxia del movimiento, me interesa mucho más llamar la atención sobre su pasado pagano. Sabemos de nuevo por Sulpicio Severo ${ }^{64}$ que Prisciliano, además de locuaz y de gran ingenio, era un intelectual, muy dado a la lectura, aunque corrompido por el estudio de las teorías del gnóstico Marco. Jerónimo ${ }^{65}$ le conecta con la pareja de gnósticos Elpidio y Ágape, y le presenta como un hombre dedicado al estudio de la magia hasta que fue nombrado obispo. Los mismos priscilianistas admitieron ese pasado pagano y se les puede considerar como parte de la nobilitas dedicada al estudio de las artes liberales y de la paideia clásica con características semejantes al emperador Juliano, Libanio de Antioquía, Sinesio de Cirene o Hipatia y conectada con las escuelas neoplatónicas y los estudios científicos de tradición pagana que se desarrollaban al amparo de los templos y de sus bibliotecas donde también participaban las mujeres ${ }^{66}$ Considero que este aspecto del priscilianismo hasta ahora no ha sido desarrollado en la dimensión que requiere y donde una de las claves principales está en las relaciones de los priscilianistas con la ciudad de Burdigala (Burdeos), unos de los principales centros de estudios superiores de Occidente, relación que no está directamente señalada por las fuentes pero que se puede deducir de los hechos.

La base de mi argumento es la conocida Commemoratio professorum Burdigalensium de Ausonio, el prefector del emperador Graciano, en la que indirectamente se relaciona a Prisciliano con los círculos intelectuales de Burdigala a los que considero perteneció. Sabemos que uno de sus rétores, un tal Dinamio, huyendo de la ley por culpa de un adulterio, acabó casado con una hispana y enseñando en la ciudad de Ilerda y que el mismo preceptor de Ausonio educado en estos círculos, Exuperio,

Tours o Ambrosio de Milán. Al respecto Sulpicio Severo, Chron. 2.49: "Priscillianus declinans in haeresem gnosticorum, per episcopos, quos sibi in eadem pravitate collegerat, Abulae episcopus ordinatur: qui aliquot episcoporum conciliis auditus Italiam petit et Romam, ubi ne ad conspectum quidem episcoporum Damasi et Ambrosii receptus cum his, cum quipus fuerat, redit ad Gallias. Inibi similiter a sancto Martino episcopo et ab aliis episcopis haereticus iudicatus appellat ad Caesarem".

63 Chron. 16. Al respecto el relato sobre la muerte y el traslado del cuerpo de Prisciliano desde la Galia a Hispania según Sulp. Sev. Chron. 2.51.8 "Peremptorum corpora ad Hispanias relata magnisque obsequiis celebrata forum funera: quin et iurare per Priscillianum summa religio putabatur".

${ }^{64}$ Chron. 2.46-50. También Jerónimo en su Ep. 35.3-4 sobre la expansión de la herejía. Un compendio del problema en Sanz Serrano 2003, 139-141.

65 "Zoroastris magi studiosissimum et ex Mago Episcopum" en Ep. 133.3. Sobre herejías y obispos: Marcos 2006, 159-168; Zuccotti 1992; sobre maniqueos: Guzmán Armario 2006, 169-176.

${ }_{66}$ Sanz Serrano 2011, 56-76. El papel de las mujeres está presente en el conflicto priscilianista, pues se les acusó de participar en reuniones y lecturas con los hombres. Al respecto Sanz Serrano 2013, 285-325. 
ejerció el cargo de juez en las provincias hispanas. Por lo tanto la ciudad cobra una importancia especial como centro de estudios de la paideia clásica al que podían acudir los intelectuales de su tiempo procedentes de otras provincias y especialmente, por su proximidad, de las hispanas entre los que se encontraban los priscilianistas. El mismo Ausonio nos informa también de la estrecha relación de estos círculos con los templos donde ejercían parte de su trabajo, tal como era el caso del rétor Acio Patera, procedente de una afamada familia de druidas de Bayocaso "del sagrado linaje del templo de Beleno" y llamado precisamente Patera por su vinculación con el culto de Apolo. De hecho el mismo Ausonio procedía de una familia que tradicionalmente ejercía la medicina en estos ambientes. ${ }^{67}$ Volviendo a los priscilianistas es sabido, y la historiografía lo ha resaltado, que tras la acusación de herejía de que fueron objeto, iniciaron un viaje hacia la corte del emperador Graciano para defenderse de las acusaciones y que en el camino hicieron un alto en Burdeos donde fueron acogidos durante un tiempo porque tenían importantes contactos en la ciudad. De allí procedían su compañera sentimental, Prócula, y la madre de ésta, Eucrocia, que eran miembros del grupo -que como dije integraba a las mujeres en el estudio y el debate intelectual-y que, al menos, la primera fue ejecutada junto a Prisciliano en Tréveris. Pero lo más relevante es que Ausonio señala que eran la hija y la esposa respectivamente de uno de los rétores más afamados de Burdigala, Delfidio, que por suerte murió antes de tener que sufrir la vergüenza de verlas condenadas y ejecutadas. Lo que hace sospechar que Prisciliano pudo haber formado parte de su círculo intelectual antes de que fuese denunciado por los obispos hispanos y así se explica la presencia de priscilianistas en la Tarraconense donde Ilerda contaba con intelectuales procedentes de esa ciudad. ${ }^{68}$ Por último quiero señalar que la epístola 120 de Jerónimo está dirigida a una noble aquitana, Hedibia, que le consultaba sobre la herejía priscilianista y que era descendiente de Patera y de Delfidio, lo que implica los intensos contactos familiares de quienes pertenecían a estas escuelas, como sucedió también, por ejemplo, en Alejandría con el círculo de Hipatia.

Por lo tanto es evidente que la formación intelectual de los líderes priscilianistas a la que aludían Sulpicio Severo, Jerónimo y otras fuentes ya señaladas tenía mucho que ver con la tradición pagana, no solo religiosa, sino también y fundamentalmente filosófica. Así lo demuestran los escritos atribuidos a Prisciliano, quien admite que acababan de salir del error, y de cuya lectura se deriva su apego a conceptos, modos, formas, ritos del paganismo tradicional difíciles de identificar como propios de un solo culto, de una fuerte influencia del neoplatonismo y de otros credos como el maniqueísmo y el gnosticismo. ${ }^{69}$ De hecho fueron condenados como tales; primero en el Concilio de Zaragoza del año 380, donde se acusaba a quienes se retiraban a sus

67 Aus. Comm. Profess. Burd. 23; en 17 habla de su preceptor Exuperio y en 4 de Patera. Toda su obra está dedicada a presentar el panorama docente de Burdeos y otras ciudades galas, pudiéndose comprobar la gran cantidad de oradores, gramáticos y rétores que impartían clases en ellas.

68 Delfidio como rétor de Burdeos cuya mujer e hija se pasaron a los priscilianistas en Aus. Comm. Profess. Burd. 5. He tratado parte de lo expuesto en Sanz Serrano 2003, 143-150. Sobre Ausonio es básico De Labriolle 1910 y el clásico de Matthews 1975, 169-180. Bibliografía y fuentes también en Blázquez 1981, 210-236, y Cardelle de Hartmann 1998, 269-290. Los contactos entre aristocracias en Occidente se pueden rastrear también en el itinerario que llevó a los priscilianistas hasta Roma, en Piay Augusto 2014, 156-176.

69 Se comprueba en Liber ad Damasum o Tractatus 2, Prisciliano Tract. 1.4-20; Tract. 3 y Liber Apologético 15, donde admiten que vivían despreocupados de Dios, en Conti 2010, 76. En el mismo sentido el hispano Orosio en su Commonitorium de errorem priscilianistarum et origenistarum (CSEL 5). Sobre los textos priscilianistas desde la hermenéutica véase Veronese 2007, 237-262. 
haciendas para escapar al control de la iglesia y se reunían con mujeres para lecturas conjuntas $;{ }^{70}$ después por un concilio en Burdeos y, finalmente, en el año 385 según Sulpicio Severo por maleficio, prácticas obscenas, reuniones nocturnas en las que participaron mujeres y orar desnudos: $:^{71}$

convictumque maleficii nec diffitentem obscoenis se studuisse doctrinis, nocturnos etiam turpium foeminarum egisse conventus, nudumque orare solitum, nocentem pronuntiavit redegitque in custodiam, donec ad Principem referet.

Por lo tanto sufrieron condena por actitudes poco convencionales desde el prisma del cristianismo, pero no en el horizonte de los rituales paganos. La condena posterior en el I Toledo del año 400 -presidido por el metropolitano de Mérida Patruino donde renegaron Dictinio y otros priscilianistas como he señalado- no solo recoge de nuevo algunas de las supuestas prácticas no ortodoxas del movimiento, sino que los obispos allí reunidos prohibieron la imposición del sacerdocio a los siervos por parte de los nobles, se supone priscilianistas, concedieron libertad a los clérigos de un obispo herético para pasarse al catolicismo y prohibieron a los penitentes acceder a altos grados eclesiásticos. ${ }^{72}$ En este concilio, como también en los posteriores que tuvieron lugar en Braga en el siglo VI convocados por Martín de Dumio, ${ }^{73}$ se percibe la pervivencia de un fuerte paganismo en las poblaciones del norte peninsular y en los supuestos círculos priscilianistas.

Con estas acciones destinadas a acabar con el movimiento que estaba fuertemente arraigado entre las poblaciones del norte se pretendía acabar también con la influencia de importantes familias - posiblemente de curiales a las que pertenecieron otros muchos intelectuales del momento como Agustín de Hipona, Libanio de Antioquía o Ausonio-a favor de otras, muy probablemente de más baja extracción social, que tomaron su lugar gracias a su conversión al cristianismo. Como sería el caso de Hidacio de Chaves quien confiesa en su obra su procedencia del territorio de los límicos (Orense), lo poco versado que estaba en estudios clásicos y su reciente conversión, pese a lo cual no tuvo problemas en ser nombrado obispo de Aquae Flaviae, quizás anteriormente en manos priscilianistas. ${ }^{74} \mathrm{La}$ importancia social de estos personajes y su poder económico está recogido no solo en los textos analizados de Sulpicio Severo, Jerónimo y otras fuentes, sino principalmente en un texto del panegirista de la corte de Teodosio Pacato ${ }^{75}$ quien asegura sin cortapisas que la condena fue por culpa de una estirpe de delatores que llevaban el nombre de obispos pero que

en la realidad eran bandidos y aún verdugos, que no contentos con despojar a los desventurados del patrimonio que habían heredado de sus mayores, los cargaban

\footnotetext{
Cs. 4 y 2 respectivamente en Vives 1983 .

Chron. 2.50.1-8

Cs. 2, 12 y 15. Sanz Serrano 2003, 149.

Vives 1963, 150-300.

Praef. y Chron. 68.

Paneg. 12.29.3: "Fuit enim, fuit et hoc delatorum genus qui nominibus antistites, se vera autem satellites atque adeo carnifices, non contenti miseros avitis evoluisse patrimonios calumniabantur in sanguinem et vitas premebant reorum iam paperum, quin etiam, cum iudicies capitalibus adstitissent, cum gemitus et tormenta miserorum auribus ac luminibus hausissent, cum lictorum arma; cum dacnaturum frena tractassent, pollutas poenali contactu manus ad sacra referebant et caerimonias quas incestaverent mentibus etiam corporibus impiaban".
} 
de calumnias hasta hacerlos morir y se cebaban en la vida de los acusados, a quienes habían ya arruinado.

Pero la condena no fue solo eclesiástica porque para llevar a cabo la requisa de los bienes y la persecución de los supuestos heréticos, la Iglesia tuvo como soporte las leyes emitidas por los emperadores. Aunque en las leyes se recogen igualmente otros mandatos imperiales como el del emperador Teodosio, de procedencia hispana y que probablemente conocía a algunos de los líderes, con el que intentó limpiar su memoria y restituirles sus bienes sin ningún éxito. ${ }^{76}$

\section{Alternativas arqueológicas al "silencio" de Hidacio}

Ante lo expuesto es evidente que las confiscaciones incluyeron los templos y lugares de culto paganos de los predios priscilianistas que en esta época todavía estarían en funcionamiento pues el proceso de cristianización fue lento. La cuestión es si algunos de estos centros pudieron haber sido el foco religioso e intelectual de donde surgieron los líderes priscilianistas como era el caso de Patera que impartía su saber en el templo de Apolo en Boyocayo o el padre de Hipatia en el Serapeo de Alejandría por poner dos ejemplos. En mi opinión Prisciliano y los principales cabecillas controlaban antes de la conversión los "dominios de los dioses" situados en los territorios patrimoniales y por ello estos lugares no volvieron a sus antiguos dueños, por otra parte ya desaparecidos, porque fueron requisados, expoliados y entregados a la Iglesia bajo el control del metropolitano de Mérida o de los obispos de la Bética, de donde partieron las primeras denuncias. Esta hipótesis explica el silencio de Hidacio respecto a los centros paganos en el norte peninsular y los efectos sobre ellos de las supuestas tropelías de los bárbaros. Tanto en el campo, donde estuvieron más expuestos al saqueo, como en los centros urbanos, donde la infraestructura eclesiástica tardó en llegar, se frenaron los intentos de cristianización de los antiguos templos y lugares de culto paganos con la persecución de los priscilianistas. Así pues, no siempre debemos culpar a los bárbaros, ya que las acciones de los cristianos no fueron menos decisivas para su desaparición y el expolio de sus riquezas como tenemos muy bien documentado gracias a la obra de Libanio de Antioquía en sus referencias a los sucesos en el imperio oriental. Este autor ${ }^{77}$ achaca en general el cierre de los dominios divinos y su destrucción a la acción de los monjes y señala como consecuencias graves el abandono de los campos que les pertenecían por parte de los campesinos, la huída de sus sacerdotes y de sus artesanos y la falta de protección en que quedaron los indigentes, los enfermos y las poblaciones locales al pasar a otras

76 C.Th. 16.10.20-24. Los emperadores y la Iglesia fueron los primeros beneficiados de todas estas actuaciones pues el emperador tenía poder para vender, donar o explotar como bienes propios las tierras y los edificios requisados como se comprueba en CJ, 2. 36.3; C.Th. 7.38.2; 6.15.21; 10.10.15-29; 16.10.13-20. Sobre la pervivencia del priscilianismo y su difusión por territorios del norte tenemos las manifestaciones de Hidacio Chron. 125; el papa León Ep. 15, Braulio Ep. 44.75-77, y el Commonitorium de Orosio, además de Sulpicio Severo Chron. 2.51.4 (CSEL 1. 104) y Dial. 3.11-13, donde dice que había ascetas en esos territorios que tuvieron miedo de caer en la persecución. Una síntesis general en Escribano Paño 1988 y Cardelle de Hartmann 1998. Más concentrados en la condena los recientes trabajos de Bravo Bosch 2010, 147-163, y Rist 2007, 197-203.

77 Lib. Pro Templis. 8 y 46-52; Orat. 2.30-32; Orat. 7.9-11.30.20. También el pagano Zósimo NH 5.23 tiene graves denuncias contra la actuación de los monjes en las ciudades y en el campo que se complementa con el testimonio del emperador Juliano en Ep. 79, 81, 111 y 115. Al respecto Sanz Serrano 1993, 455-462. 
manos; incluso cómo los edificios terminaron convertidos en depósitos de escorias o de leña y sus materiales reutilizados para la construcción de casas.

En la Crónica de Hidacio, un cristiano, falta precisamente toda esta información relativa a los efectos en los templos paganos de la acción de las masas cristianas o de los propios priscilianistas primero y después de las acciones de rapiña de los bárbaros. Pero el autor sí recoge las escasas destrucciones de iglesias urbanas por los bárbaros como hemos visto, escasas porque escasa era la difusión del cristianismo en gran parte de las Hispanias. Ante el silencio premeditado se plantean varios interrogantes. El primero si Prisciliano y los cabecillas del movimiento se ocupaban de los templos paganos de sus dominios, ejerciendo algún tipo de sacerdocio como parece vislumbrarse, y al pasarse al cristianismo ellos mismos colaboraron en su cierre y el abandono "oficial" del culto aunque las poblaciones continuasen con sus antiguas creencias; de este modo los bárbaros no pudieron saquearlos más que en sus estructuras y materiales de construcción, no en sus riquezas, de ahí el comprensible silencio de Hidacio. En este caso, su crónica habría dejado constancia del saqueo de las supuestas iglesias construidas por los priscilianistas en esos espacios sagrados, lo que no es el caso, y este testimonio remite exclusivamente a los pocos casos de Braga, Astorga y Tarazona en el norte, además de las de Mérida e Híspalis. Por otra parte, y siguiendo de nuevo a Libanio, la destrucción de templos no significó el inmediato final de las creencias, pues las gentes siguieron acudiendo a los mismos lugares sagrados ya vacíos para orar y sacrificar a sus dioses, razón por la que los obispos y sacerdotes aprovecharon esos lugares y los materiales de las construcciones paganas para construir sus iglesias y los antiguos renteros y dependientes se convirtieron en la familia ecclesiae de los grandes predios eclesiásticos ${ }^{78}$ Esa fue la primera intención de Prisciliano al pasarse al cristianismo y posteriormente de otros domini como Paulino de Nola en los dominios de su esposa en la Tarraconense, mientras en época visigoda fue ya un hecho perfectamente documentado en la nobleza hispana a cuyos esfuerzos debemos construcciones tan bien conocidas como Santa Lucía del Trampal en Cáceres, San Pedro de la Mata en Toledo, Quintanilla de las Viñas en Burgos o Santa Comba de Bande en Orense entre otras muchas. ${ }^{79}$

Por lo tanto la clave para refutar las noticias manipuladas o "el silencio" de Hidacio está en la arqueología y en los sólidos argumentos que pueda aportar. Y en este campo propongo algunas vías que considero muy sugestivas y que hasta el momento han sido estudiadas con otros planteamientos. La primera es la revisión del estudio de los tesorillos del noroeste peninsular en su aspecto cronológico y contextual y como posible fenómeno de tesaurización en una geografía religiosa y no solo civil como se ha venido haciendo hasta ahora. ¿Se pueden corresponder algunos de los abundantes tesoros hallados con los dominios de los dioses paganos situados en las

78 Lib. Orat. 30.20. Estoy de acuerdo con la tesis de Piay Augusto 2011, 271-300, de que a los priscilianistas hay que buscarlos en las villas donde tenían sus posesiones. Pero también, como hemos visto, en las ciudades porque la ciudad y su territorio forman siempre un conjunto inseparable. El autor llama la atención sobre el hecho de que la arqueología está descubriendo nuevos asentamientos y señala ya en la Galicia actual hasta 100 supuestas villas. La bibliografía es tan extensa que remito a su trabajo. En general se puede consultar igualmente Álvarez Solano - Hurtado Buscató - Rivas García 1999, 275-300, y Enjuto Sánchez 2000, 407-423.

79 Melania intentó lo mismo a principios del siglo $\mathrm{V}$ en el norte peninsular pero no pudo por la presencia de los bárbaros, como se ve en Paladio (H.Laus. 54) y Geroncio (Vit. Mel. 11-40). En época visigoda los ejemplos se multiplicaron con grandes constructores de latifundios cristianos como Braulio de Zaragoza, Fructuoso de Braga, Millán de la Cogolla o Justiniano de Valencia. Sobre las transformaciones una síntesis en Castellanos 2004 . 
principales vías de comunicación por las que también deambularon los bárbaros? $?^{80}$ Sinesio de Cirene ${ }^{81}$ atestigua las depredaciones que éstos realizaron en centros cristianos y en tumbas en el norte de África que les reportaron grandes riquezas. En este sentido quizás debamos considerar de esta procedencia el rico botín que sacaron los suevos de su batalla contra Andevoto antes señalada y que no tiene por qué suponerse procedente solo de predios laicos. La segunda propuesta y complementaria de la anterior es el estudio arqueológico de los centros de culto paganos que se conocen enclavados en las principales vías por las que se movieron suevos, vándalos y alanos en la crónica hidaciana, algunos de ellos situados en lugares de difícil acceso, originarios de cultos prerromanos y sin todavía una estructura eclesiástica en la zona. En este caso, pueden dar mejores resultados los situados en el campo ya que en las ciudades los trabajos arqueológicos suelen dar peores frutos por el uso continuado de los espacios. Pues solo con excavaciones sistemáticas y estudios en los que se mire también hacia un pasado pagano y las transformaciones producidas en época cristiana podremos dar sentido al panorama religioso peninsular en los siglos $\mathrm{V}$ al VII. También tendremos que prestar atención a casos concretos que están en proceso de estudio como son los 100 epígrafes del santuario de Berobreo excavado por Th. Schattner en la península del Morrazo en Pontevedra, ${ }^{82} \mathrm{o}$ al significado y pervivencia del santuario de Endovélico en San Miguel de Mota -en Alandroal, Évora- con sus altares, estatuas destrozadas intencionadamente e inscripciones ${ }^{83}$ Igualmente hay que dar una respuesta cronológica e histórica definitivas a los supuestos lugares de culto a Ataecina Turibrigense, Santa Eulalia de Bóveda, San Miguel de Vizella y otros muchos santuarios enclavados en las rutas hidacianas pendientes de excavar, así como a villas como la Quinta das Longas en Elvas (Portugal), donde se han encontrado signos de destrucción violenta de sus espacios religiosos en época tardía. ${ }^{84}$

De las respuestas que demos a la destrucción en el norte de los hipotéticos "dominios de los dioses" depende el significado de los textos de los siglos VI y VII que denuncian la pervivencia del paganismo en esa época. Tras el silencio de Hidacio contamos con el testimonio, pocas décadas después, del obispo Martín de Dumio acerca de las observatio paganismi de los habitantes de la Gallaecia y la todavía existencia de festividades como las Paganalia, Lupercalia, Vulcanalia y las Kalen-

80 Los bárbaros se hicieron con grandes tesoros en otros recorridos como en Pietroasa en los Cárpatos o el de Childerico en Tournai. Al respecto Schmauder 2003, 79-94; Hardt 2003, 95-107.

81 Orat. 2.3.302.

82 Schattner - Suárez Otero - Koch 2005, 135-183. Aunque su cronología final todavía no está fijada, parece que el santuario tuvo una pervivencia en época tardía; de él provienen más de ciento veinte estelas dedicadas al dios Berobreo, de factura muy mala y con símbolos propios del mundo indígena, soles y decoraciones geométricas; por las monedas se le considera en uso todavía en el siglo $\mathrm{V}$ d.C.

83 Sobre toda esta problemática Sanz Serrano 2013, 43-50. Aunque el santuario necesita ser excavado, sabemos que hay monedas tardías y estatuas destruidas. Véase Guerra - Schattner - Fabião - Almeida 2005, 184-234.

84 Caballero - Berrocal - Rangel 2004, 149-160. Suelen ser santuarios en encrucijadas de caminos y relacionados con lugares con aguas curativas que después fueron cristianizados como el de Ataecina con Santa Lucía. Pero están necesitados de excavaciones sistemáticas. La rapiña se vislumbra en las iglesias superpuestas a antiguos recintos que han sido interpretados como villas pero en ningún caso se han estudiado como posibles santuarios o dominios de los dioses cuando se han excavado como serían los casos de Veranes en Gijón, Torre de Palma y Milreu en Portugal, La Cocosa en Badajoz, todas ellas con ninfeos y en especial la villa de Quinta das Longas en Elvas, también con un ninfeo y abandonada no antes del siglo $\mathrm{V}$ y después de ser destruidas sus estatuas que los excavadores hallaron juntas como sucedía en el santuario de Endovélico. Al respecto Nogales Basarrate 2004 y Sanz Serrano 2003, 40-80 con las fuentes relativas a la destrucción de templos. Sobre la importancia de estos santuarios remito a Cox Miller 1994. 
das con la observancia de sus ritos. ${ }^{85}$ Los usos y costumbres religiosas paganas están presentes igualmente en las denuncias de los concilios que el sacerdote convocó en Braga en los años 561 y 572 para conseguir la sanción eclesiástica y la ayuda de la nobleza que necesitaba para su erradicación. ${ }^{86}$ Denuncias muy semejantes a las que los obispos hispanos pronunciaban en otros marcos geográficos de la Península en distintos concilios de época visigoda y que atribuían a las artes del diablo y al ejercicio de la magia propia de los paganos. ${ }^{87}$ Pero sobre todo hay que centrar la atención en el temor de los monarcas visigodos -que se trasluce en los cánones conciliareshacia una aristocracia provincial opositora y consolidada, apegada a sus tradiciones y creencias paganas, que se identifica como patrona de masas de siervos a los que podía movilizar incluso militarmente, y al mismo tiempo como dueña de las magistraturas y cargos; aristocracia poderosa a la que temían los jueces, los abades y los obispos y que no dudó en desestabilizar a la propia monarquía visigoda hasta la llegada de los norteafricanos. Lo que pone en cuestionamiento las teorías demasiado extendidas de que el paganismo peninsular fue un fenómeno residual entre las masas más empobrecidas a partir de principios del siglo $\mathrm{V}^{88}$

Para concluir, es evidente que la Crónica del obispo Hidacio de Chaves, pese a su interés por borrar de la historia a los paganos en el norte de Hispania, no consigue ocultarlos. La damnatio memoriae a que les condenó, el "silencio de Hidacio", ha dejado la huella de su acción en su misma obra y esa huella se documenta en otros testimonios de la época. Tampoco logra superar las más que evidentes contradicciones con otras fuentes literarias y arqueológicas su interés por testificar un cristianismo fuertemente afianzado en la Gallaecia. Aunque sí es cierto que el fenómeno priscilianista en el que se detiene con interés responde a las primeras fases de expansión de la nueva religión por espacios que antes eran "dominios de los dioses". Por lo tanto, en su conjunto, la obra es de gran utilidad como fuente histórica pero debe ser utilizada con cautela por su fuerte carga ideológica y, aunque en ella los datos son muy importantes para entender las transformaciones religiosas que tuvieron lugar en el siglo $\mathrm{V}$ en las Hispanias, también los son sus cuidados e intencionados silencios.

85 De corr. rust. 10-16.

86 Cánones 1, 69, 73 y 78 del Concilio II de Braga sobre todo; el primero atribuye estas creencias a los gentiles que vagaban en el ocio y se dedicaban a las "iniquas observationes agere kalendarum”, que eran prácticas paganas "paganorum consuetudinem" del canon 71, algunas de cuyas especialidades son recogidas en los distintos cánones. Al respecto Vives 1963 y Sanz Serrano 2003, 56-60.

87 Que ya habían sido perseguidos en época clásica al incluirse en ellas actos y rituales religiosos no controlados por el estado. Como visión de conjunto Fernández Uriel 2006, 35-55; Janowitz 2001. Algunos ejemplos de cánones conciliares son el canon 16 del III Concilio de Toledo, 29 del IV Concilio de Toledo, el 11 del XII Concilio de Toledo y el 2 del XVI. Remito a mi trabajo Sanz Serrano 2003, 70-95.

88 Sanz Serrano 2009, 289-296, y 570-592. Las leyes visigodas también aluden a estos actos que son perseguidos civilmente como se comprueba en $L$ V. 6.2.4: "Malefici vel inmissores tempestatum, qui quibusdam incantationibus grandines in vineis messibusque inmittere peribentur, vel hii, qui per invocationem demonum mentes hominum turbant, seu qui nocturna sacrificia demonibus celebrant eosque per invocationes nefarias nequiter invocant". La 6.2.3 asegura que lo practicaban tanto los siervos como los libres y la 6.2.1 que algunos con estos actos atentaban contra la salud de los príncipes con lo que se ve la dimensión del problema. Sobre este tipo de aristocracia remito a mi trabajo Sanz Serrano 2007, 443-480. Sobre las transformaciones ideológicas que se produjeron en los siglos IV y V son clásicos Mac Mullen 1984; Mazza 1986 y Momigliano (ed.) 1963. 


\section{Referencias bibliográficas}

Álvarez Solano, F. E. - Hurtado Buscató, R. - Rivas García, O. (1999): "La economía de Dios: la construcción de un santuario cristiano según los carmina natalicia de Paulino de Nola", Arys 2, 275-300.

Bairrão, J. M. - Étienne, R. (1965): "Les résultats de la première campagne de fouilles franco-portugaises à Conimbriga (Portugal)", Comptes rendus des séances de l'Académie des Inscriptions et Belles-Lettres 109/2, 421-451.

Beard, M. (1991): "Writing and religion: Ancient Literacy and the function of the written word in Roman religion", [en] J. H. Humphrey (ed.), Literacy in the roman world (=JRA, Suppl. 3), Ann Arbor, 35-58.

Blázquez, J. M (1981): "Prisciliano, introductor del ascetismo en Gallaecia", [en] I Reunión gallega de estudios clásicos, Santiago de Compostela, 210-236.

Bravo, G. - González Salinero, R. (eds.), (2006): Minorías y sectas en el mundo romano. Actas del III Coloquio de la AIER (=Signifer. Monografías y Estudios de Antigüedad Griega y Romana 20), Madrid.

Bravo Bosch, M J. (2010): "El iudicium publicum de la causa contra Prisciliano", Studia et Documenta Historiae et iuris LXXVI, 147-163.

Caballero, L. - Berrocal-Rangel, L. (2004): "El control de los caminos como recurso: el entramado viario de la Beturia Céltica", [en] J.-G. Gorges - E. Cerrillo - T. Nogales (eds.), V Mesa Redonda Internacional sobre Lusitania romana: Las comunicaciones, Madrid, 149-160.

Cameron, A. (1985): Literature and Society in the Early Byzantine World, London.

Cameron, A. - Long, J. (1993): Barbarians and politics at the court of Arcadius (=Transformation of the Classical Heritage 19), Berkeley-Los Angeles-Oxford.

Cardelle de Hartmann, C. (1998): "El priscilianismo tras Prisciliano, ¿un movimiento galaico?", Habis 29, 269-290.

Castellanos, S. (2004): La hagiografía visigoda. Dominio social y proyección cultural, Logroño.

Conti, M. (2010): The complete Works. Introduction and Commentary, Early Christian Texts, Oxford.

Corradini, R. - Diesenberger, M. - Reimitiz, H. (eds.), (2003): The Construction of Communities in the Early Middle Ages. Texts, Resources and Artefacts (=Transformation of the Roman World 12), Leiden.

Cox Miller, P. (1998): Dreams in Late Antiquity. Studies in the Imagination of a Culture, Princeton.

Cruz, N. (2010): “¿Personas informadas en el Mediterráneo Antiguo?”, [en] N. Cruz - C. Balmaceda, La Antigüedad. Construcción de un espacio interconectado, Santiago de Chile, 235-272.

De Labriolle, A. (1910): Un épisode de la fin du paganisme: la correspóndance d'Ausone et de Paulin de Nole, Paris.

Enjuto Sánchez, B. (2000): "Las disposiciones judiciales de Constantino y Juliano a propósito de las tierras de los templos paganos", Gerión 18, 407-423 (http:// dx.doi.org/10.5209/GERI.15206).

Escribano Paño, $\mathrm{M}^{\mathrm{a}}$ V. (1988): Iglesia y Estado en el certamen priscilianista. Causa ecclesiae y iudicium publicum (=Universidad de Zaragoza. Monografías de Historia Antigua 3), Zaragoza. 
Fernández Uriel, P. (2006): “Minorías intelectuales, políticas y religiosas en época Julio-claudia”, [en] Bravo - González Salinero (eds.), 2006, 35-55.

Fowden, G. (1993): Empire to Commonwealth. Consequences of Monotheism in Late Antiquity, Princeton.

Guerra, A. - Schattner Th. G. - Fabião, C. - Almeida, R. (2005): "São Miguel da Mota (Alandroal/Portugal) 2002. Bericht über die Ausgrabungen im Heiligtum des Endovellicus", MM 46, 184-234.

Guzmán Armario, F. J. (2006): "Los maniqueos en la parte oriental del Imperio romano durante los reinados de Diocleciano y Constantino (284-337)", [en] Bravo - González Salinero (eds.), 2006, 169-176.

Hagl, W. (1997): Arcadius Apis Imperator. Synesios von Kyrene und sein Beitrag zum Herrscherideal der Spätantike, Stuttgart.

Halm, C. (1866): Corpus Scriptorum Ecclesiasticorum Latinorum. I, Viena (=CSEL)

Hardt, M. (2003): "The nomad's greed for gold: from the fall of the burgundians to the avar treasure", [en] Corradini - Diesenberger - Reimitiz (eds.), 2003, 95-107.

Janowitz, N. (2001): Magic in the Roman World. Pagans, Jews and Christians, London-New York.

Joannou, P. P. (1993): La législation imperiale et la christianisation de l'Empire Romain (=Orientalia Christiana Analecta 192), Roma.

Le Bohec, Y. (2005): Histoire de l'Afrique Romaine (146 avant J.-C.-439 après J.C.), Paris.

Lepelly, C. (2001): Aspects de l'Afrique romaine, Bari.

Marcos, M. (2006): "Definiendo al hereje en el cristianismo antiguo. Los tratados De haeresibus", [en] Bravo - González Salinero (eds.), 2006, 159-168.

Mac Mullen, R. (1984): Paganism in the Roman Empire, New Haven-London.

Matthews, J. (1975): Western Aristocracies and Imperial Court (364-425), Oxford.

Mazza, M. (1986): Le maschere del potere. Cultura e politica nella tarda antichitá (=Collezione di opere giuridiche e storiche 1), Napoli.

Momigliano, A. (ed.), (1963): The Conflict between Paganism and Christianity in the Fourth Century, Oxford.

North, J. A. (2000): Roman Religion, Oxford.

Piay Augusto, D.

(2010): "Asturica Augusta un posible destino para las reliquias de Prisciliano", Astorica: revista de estudios, documentación creación y divulgación de temas astorganos 29, 67-88.

(2011): “Arqueología y priscilianismo”, Hispania Antiqua 35, 271-300.

(2014): “...At tum Instantius, Salvianus et Priscillianus Romam profecti: el viaje de los priscilianistas hacia la ciudad eterna", Antiquité Tardive: revue internationale d'histoire et d'archéologie 22, 156-176.

Rist, J. (2007): "Violencia estatal al servicio de la Iglesia. La ejecución de Prisciliano en 385 y la política religiosa imperial”, Agustinus 52, 197-203.

Sanz Serrano, R.

(1986): "La excomunión como sanción política en el reino visigodo de Toledo", Antigüedad y Cristianismo 3, 275-288.

(1993): "Julian Apostata in Kleinasien", Instanbuler Mitteilungen 43, 455-462. (2003): Paganos, adivinos y magos. Análisis del cambio religioso en la Hispania Tardoantigua (=Gerión Anejos. Anejo VII), Madrid. 
(2006): "El nieto vestido de púrpura: Euquerio y Estilicón”, [en] G. Bravo - R. González Salinero (eds.), Crisis en Roma y las soluciones desde el poder. Actas del III Coloquio de la AIER (=Signifer. Monografías y Estudios de Antigüedad Griega y Romana 47), Madrid, 291-313.

(2007): "Aristocracias paganas en Hispania tardía (s. V-VII)", [en] D. Plácido Suárez - F. J. Moreno Arrastio - L. A. Ruiz Cabrero (eds.), Necedad, sabiduría y verdad: el legado de Juan Cascajero (=Gerión 25/1), Madrid, 443-480 (http:// dx.doi.org/10.5209/GERI.14859).

(2011): "The Seclusion of the Orator and the Decline of Hellenistic Paideia in the Christian Empire", [en] D. Hernández de la Fuente (ed.), New Perspectives on Late Antiquity, Newcastle upon Tyne, 56-76.

(2013): "Hipatia versus Cirilo de Alejandría: ciencia, religión y muerte al final de la Antigüedad", [en] F. García Romero - A. Moreno Hernández (eds.), Enemistades peligrosas. Encuentros y desencuentros en el Mundo Antiguo, Madrid, 285-325.

Schattner, Th. G. - Suárez Otero, J. - Koch, M. (2003): "Monte do Facho 2003. Bericht über die Ausgrabungen im Heiligtum des Berobreus", MM 46, 135-183.

Schmauder, M. (2003): "The "Gold Hoards" of the early migration period in southeastern Europe and the Late Roman Empire", [en] Corradini - Diesenberger Reimitiz (eds.), 2003, 79-94.

Veronese, M. (2007): "Tempora gravia et periculosa: il caso Prisciliano", Auctores Nostri, Studi e testi di litteratura cristiana antica 5, 237-262.

Vives, J. (1963): Concilios visigóticos e hispano-romanos (=España Cristiana. Textos 1), Madrid-Barcelona.

Zuccotti, F. (1992): Furor haereticorum. Studi sul trattamento giuridico de la follia e sulla persecuzione della eterodossia religiosa nella legislazione del tardo impero romano $(=$ Università degli Studi di Milano. Facoltà di Giuriprudenza. Pubblicazioni dell'Istituto di Diritto Romano 26), Milano. 